\title{
Maternal Self-Confidence during Puerperal Period among Primipara
}

\section{Adolescent Mothers}

\author{
Reda Mahmoud Mohamed Hables, Lecturer \\ Obstetrics and Gynecological Nursing, Faculty of Nursing, Alexandria University \\ Naglaa Zaki Hassan Roma, Lecturer \\ Obstetrics and Gynecological Nursing, Faculty of Nursing, Alexandria University
}

\begin{abstract}
Adolescence is a transitional period between childhood and adulthood. It is characterized by major biological, psychological, and social changes. When an adolescent becomes pregnant, her psychological adjustment to her expected motherhood is added to her adolescence challenges. Objective: Assess maternal self- confidence among first time puerperal adolescent mothers. A descriptive research design was utilized. Setting: Four primary health care centers in Hafr Albatin city. Namely Alkhalidia, Alsolumania, Alfisalia and Alazizaia center. Subjects: A convenience sample of 160 postpartum women during early postpartum period. Tool: A structured interview schedule was used. It consists of two parts. It includes (a) Subjects' demographic characteristics, (b) Reproductive history, (c) Maternal Self-Confidence Scale (lips maternal self-confidence scale (LMSCS). Results: The study revealed that $65 \%$ of its subjects had low maternal self-confidence. Significant correlations (0.01) were observed among self-confidence level and age, income, and parity. Conclusion: More than half (65\%) of the study subjects had low self-confidence level. There was a positive Correlation between it and age, income, and parity. Recommendations: Primipara mother should be encouraged to participate in prenatal classes and forming a network with other prenatal class participants.
\end{abstract}

Keywords: Adolescence; Motherhood; Postpartum; Self-confidence.

\section{Introduction}

Adolescence is a period of transition between childhood and adulthood. Female who are entering adolescence are going through many changes (physical, intellectual, psychologically and social developmental). Adolescent or teenage pregnancy is a global problem that occurs in high, middle, and low income countries. Around the world, adolescent pregnancies are more likely to occur in marginalized communities, commonly driven by poverty and lack of education and employment opportunities $^{(1)}$. Worldwide, approximately 750 million girls and women are married before the age of 20. In the developing countries, about 16million adolescent mothers aged 15-19 years and 2.5 million girls below 16 years give birth each year ${ }^{(2,3)}$.

Many women do not completely return to their pre-pregnancy condition within 6 weeks after delivery, which is considered the postpartum period. The postpartum period is characterized by a revival of the pregnancy and birth experiences, as well as adjustment to new roles, beside the adjustment of the family to the new family member. The postpartum period is defined as "the six weeks after childbirth" ${ }^{\prime(4,5)}$. In this period the mother usually experience many changes, both physically and emotionally. In the case of a first baby, it also represents a developmental milestone for the man and woman whose lives will no longer be unfettered. Adequate education in accordance with the needs of women is necessary to enable them to handle changes in the postpartum period and to meet these demands ${ }^{(6)}$.

For women in communities where motherhood is highly desired, motherhood is considered crucial to the woman's identity. Teenage motherhood, occurring at a critical developmental stage has been identified as having adverse social and health 
consequences. Early positive orientation towards motherhood has been associated with teenage pregnancy where girls are made to feel that motherhood is a prerogative in their lives as women and central to female gender roles ${ }^{(7,8)}$.

Motherhood is a significant and important aspect of life for many women around the globe. Transition to motherhood, is a challenging and stressful process in postpartum period as the women not only face new tasks associated with the new maternal role but also the dramatic changes in their bodies. Maternal self-confidence is defined as the mother's perception of her own ability to take care of the infant and understanding his/her needs ${ }^{(9)}$.

Maternal self- confidence entail accepting the maternal role, being able to facilitate maternal role development, improve neonatal outcomes, and promote infant nurturing and development. Higher confidence causes the mother to feel more complete in her maternal role. It also plays a critical role in influencing maternal competence and parenting stress, so that maternal competence can mitigate parental stress $^{(10,11)}$.

If becoming a mother in the postpartum period goes well, the mother can expand her self-confidence in her maternal role, loving the newborn, and accepting her new personality and role as a mother. Lack of maternal knowledge, experience and skills reduces self-confidence. If the mother lacks self-confidence in the care for her infant in the early postpartum period, it may become a negative motherhood experience, causing her to fail properly in taking care of her newborn. This negative feeling can affect the bonding between the mother and the baby after birth ${ }^{(11,12)}$.

\section{Aim of the Study}

The study aimed to assess maternal self- confidence among first time puerperal adolescent mothers.

\section{Research Question}

What is the self-confidence level among first time puerperal adolescent mothers?

\section{Materials and Method}

\section{Materials}

Design: A descriptive study was adopted.

Setting: The study was conducted at Hafr Albatin city. Data was collected from four primary health care centers (PHC). The four centers namely; Alkhalidia, Alsolumania, Alfisalia and Alazizaia.

Subjects: A convenience sample of 160 first time puerperal adolescent women attending the above mentioned settings were selected for this study. 40 women were selected from each of the previously mentioned centers.

Tool: A structured interview schedule was used to collect the necessary data. It entailed two parts:

\section{Part I:}

This part included questions about:

a) Subjects' socio-demographic characteristics such as age, level of education, occupation, type of family, and monthly income.

b) Reproductive history of the study subjects such as gravidity, parity, number of abortion, type of delivery, sex of living children and attendance for antenatal class.

\section{Part II:}

c) Maternal Self-Confidence Scale (Lips Maternal Self-Confidence Scale (LMSCS)): The scale contains 24 self- report positive-negative statement to assessed the maternal self-confidence regarding child care. It contains 5 dimension measuring mother's confidence in her ability to assume new responsibility based on 5 areas, namely; infant care, self- care, household, social and community and occupational activities. It consists of 
14 questions rated on a 3-point Likert scale with higher scores indicating higher self-confidence in the maternal role.

Then subjects total scores ranged between (14-42). Each subject's level was ranked as negative, Moderate and positive according to the developed score. The highest score was conveying positive self-confidence. Women's total scores were classified as follows:

- Negative $<23$

- Moderate $23-<32$.

- $\quad$ Positive $\geq 32$.

\section{Method}

The study was executed according to the following steps:

- Approval of ethical committee was obtained.

- An official letters from the authorities was directed to the previously mentioned settings to obtain their permission to conduct the study.

- A structured interview schedule was developed by the researcher based on an extensive review of relevant and recent literature. It was tested for content validity by 5 juries, who are experts in the related field. Tool's reliability was tested by Cronbach's Alpha coefficient test that indicates an accepted reliability of the tool (0.877).

- A pilot study was carried out on 16 woman (excluded from the sample) to ascertain the clarity and the applicability of the tool as well as to estimate the time needed to complete it.

- Data were collected through the interviewing technique where each subject was individually interviewed before or after her visits.
- The researcher explained the purpose of the study to each woman, and then written consent to participate in the study was obtained from them. Each interview was conducted individually and in total privacy to assure that the obtained information will be confidential and will be used only for the purpose of the research.

\section{Ethical considerations:}

For each recruited subject the following issues were considered: securing the subject's informed written consent, keeping her privacy and right to withdrew at any time as well as assuring confidentiality of her data.

\section{Statistical Analysis}

Data analysis was carried out on window XP using statistical Package for Social Sciences (SPSS) version 21 program. The collected data was categorized, coded, computerized, tabulated and analyzed.

\section{Results}

Table (1) shows that more than one third $(38.75 \%)$ of the study subjects were teenagers, while $43.75 \%$ of them aged 1517 year, more than one half $(50.0 \%)$ of them have university education, $68.75 \%$ were housewife, live in extended family and have enough income $(51.25 \% \quad \& \quad 62.5 \%)$ respectively.

Table (2) shows that the majority (90\%) of the study subjects were primigravidas. More than one have $(55 \%)$ of them delivered through normal vagina. $75 \%$ of them have a male baby. $87.5 \%$ reported this pregnancy was planned. $80 \%$ of the study subject was reported attain to the antenatal class regularly.

Table (3) illustrates the level of maternal self-confidence among the study participants. It was obvious that mean of the total score of maternal self-confidence was $36.77 \pm 4.28$. Where $17.5 \%$ of the study subject have positive maternal selfconfidence, while $43.75 \%$ and $38.75 \%$ have 
negative and moderate maternal selfconfidence regarding child care respectively.

Table (4) reveals a statistical significant correlation between level of maternal selfconfidence and age $(\mathrm{P}=0.001)$, types of family $(\mathrm{P}=0.005)$, income of mother $(\mathrm{P}=0.001)$. Where $3.2 \%$ of the study sample less than 15 year have negative maternal confidence, $67.7 \%$ of the study sample who are live in nuclear family have negative maternal confidence, and $64.3 \%$ of the sample have enough income have positive maternal confidence.

Table (5) shows a statistical significant correlation was detected between the study subjects reproductive history and their maternal self-confidence relation to methods of delivery $(\mathrm{P}=0.001)$, pregnancy planed $(\mathrm{P}=0.001)$ and attendance of antenatal visits $(\mathrm{P}=0.000)$.

\section{Discussion}

During the teenage years, young people who are faced with early motherhood may experience conflict between their new position as mothers and feeling of maternal self-confidence and their adolescent needs. The experiences of early motherhood are contextual, influenced by culture and the society within which the teenager/woman lives and a common problem worldwide. It expresses low levels of self-esteem, especially in cases of low levels of education and economic status ${ }^{(13,14)}$.

This study aimed to assess maternal selfconfidence among first time puerperal adolescent mothers.

The current study revealed that $43.75 \%$ of the study subjects have negative maternal self-confidence regarding child care. (Gyesaw, 2013) reported in the study about experiences of pregnancy and motherhood among teenage mothers, during the teenage years young people who are faced with early motherhood may experience conflict between their new position as mothers and their adolescent needs. Where the experience of early motherhood is contextual, influenced by culture by culture and the society within which the teenage women lives.

The study revealed that significant correlation between age and maternal selfconfidence $(p=0.0001)$, where teenage subjects have negative self-confidence. The suggestion for this different due to adolescents and adult mother may be different in emotional maturity and emotional support opportunities. The finding agrees by the findings of Josephine, (2017). He had reported that, causes of low selfconfidence among young mothers were lack of emotional and social maturity and the identity formation that adult mothers possess. Where young adolescent mother may have negative and low self -confidence regarding maternal role, due to lack of the emotional and social maternity and the identity formation that adult mothers process. On the other hand, adult women usually feel that new born is big value important and positive value in their lives and should be kept ${ }^{(15)}$.

The finding of this study revealed no significant relation between level of mother's education and level of maternal selfconfidence. Where many participants stated that education was important, but they had no definite plans for achieving or continuing their educational goals. This result contradicts with the study findings of another (Mimmie, 2015), He reported that, higher level of education have positive selfperceptions of parenting and feelings of how important the infant was to her life ${ }^{(16)}$.

The current study revealed significant correlation between mother's income and level of maternal self-confidence $(\mathrm{p}=0.001)$. Where $65.5 \%$ of mother with enough income showed positive self-confidence regarding maternal role and child care than mothers with low or not enough monthly income. This finding indicates that mother with higher economic level are more adaptive to the postpartum maternal role. These findings are similar to the study of (Rikuya, 20015). Who reported that mothers 
with a high economic status adapted to the maternal role better than mother with low or unstable economic status ${ }^{(17,18)}$.

Regarding planning for pregnancy, the study findings indicates a significant correlation between planning for pregnancy and maternal self-confidence $(\mathrm{P}=0.001)$. The finding may be due to the fact that age of most proportion of the study subjects were 20-25 year, newly marriage, wanted to become mother and developed the new family.

Regarding participation in antenatal classes, the present study findings a significant relation between attendance of antenatal classes and maternal selfconfidence after delivery $(\mathrm{P}=0.001)$. This finding reflects the positive effect of antenatal education on maternal selfconfidence regarding the maternal role, and preparation for motherhood more easy with enough information and guideline. This finding goes on line with the study of (Oh and Kim, 2012). He reported that group of mother that received prenatal education before delivery showed a more significant difference in postnatal self-confidence regarding the maternal role than a group that did not receive it ${ }^{(19,20)}$.

\section{Conclusion}

Based on the findings of the current study it could be conclude that, More than half $(65 \%)$ of the adolescent mothers in Hafer Albatin city had low maternal selfconfidence and had a statistically significant correlation was detected between their age, income, planned pregnancy and attendance with antenatal classes and level of maternal self-confidence.

\section{Recommendations}

- The findings suggest the need for community health promotion and public health intervention to improve maternal and child health among early married mother.

- Encourage to a activity participate in prenatal classes and get help from exchange of information by forming network with prenatal class

- Prepare prenatal class programs

- Delayed the age of marriage

- The adolescent motherhood should be continuously periodically evaluation of its impacts on population health status. 
Table (1): Distributions of the study subject according to their socio-demographic characteristics

\begin{tabular}{|c|c|c|}
\hline Data & No. & $\%$ \\
\hline \multicolumn{3}{|l|}{ Maternal age } \\
\hline$-\quad \leq 15$ & 28 & 17.50 \\
\hline$-\quad 15-17$ & 70 & 43.75 \\
\hline$-\quad \geq 17$ & 62 & 38.75 \\
\hline \multicolumn{3}{|l|}{ Educational level } \\
\hline - $\quad$ Primary & 20 & 12.50 \\
\hline $\begin{array}{ll} & \text { Secondary } \\
\end{array}$ & 60 & 37.50 \\
\hline - University & 80 & 50.00 \\
\hline \multicolumn{3}{|l|}{ Occupation } \\
\hline - Employer & 50 & 31.25 \\
\hline - $\quad$ Housewife & 110 & 68.75 \\
\hline \multicolumn{3}{|l|}{ Types of family } \\
\hline - Nuclear & 78 & 48.75 \\
\hline - $\quad$ Extended & 82 & 51.25 \\
\hline \multicolumn{3}{|l|}{ Income } \\
\hline - $\quad$ Not enough & 60 & 37.50 \\
\hline
\end{tabular}

Table (2): Distributions of the study subject according to their reproductive history

\begin{tabular}{|l|c|c||}
\hline \multicolumn{1}{|l|}{ Data } & No. & \% \\
\hline Gravidity & 144 & 90 \\
\hline$-\quad$ First time & 16 & 10 \\
\hline$-\quad$ Abortion & \multicolumn{2}{||}{} \\
\hline Methods of delivery & 88 & 55 \\
\hline$-\quad$ Vaginal delivery & 72 & 45 \\
\hline$-\quad$ c-Section & 120 & 75 \\
\hline Gender of baby & 40 & 25 \\
\hline$-\quad$ Male & \multicolumn{2}{||}{} \\
\hline$-\quad$ Female & 140 & 87.5 \\
\hline Pregnancy planed & 20 & 12.5 \\
\hline$-\quad$ Planed & 128 & 80 \\
\hline$-\quad$ Not planed & 32 & 20 \\
\hline Attendance of antenatal visits & \multicolumn{2}{|l||}{} \\
\hline$-\quad$ Yes
\end{tabular}

Table (3): Distributions of the study subject according to their level of Maternal Self Confidence

\begin{tabular}{|c|c|c|}
\hline Maternal self - confidence & No. & $\%$ \\
\hline - $\quad$ Negative & 70 & 43.75 \\
\hline - Moderate & 62 & 38.75 \\
\hline - $\quad$ Positive & 28 & 17.5 \\
\hline $\mathrm{M} \pm \mathrm{SD}$ & \multicolumn{2}{|c|}{$36.77 \pm 4.28$} \\
\hline
\end{tabular}


Table (4): Correlation between the study subject according to their socio-demographic characteristics and maternal confidence

\begin{tabular}{|c|c|c|c|c|c|c|c|}
\hline \multirow{2}{*}{ Data } & \multicolumn{2}{|c|}{$\begin{array}{c}\text { Negative } \\
(\mathrm{N}=62)\end{array}$} & \multicolumn{2}{|c|}{$\begin{array}{c}\text { Moderate } \\
(\mathrm{N}=70)\end{array}$} & \multicolumn{2}{|c|}{$\begin{array}{c}\text { Positive } \\
(\mathrm{N}=28)\end{array}$} & \multirow[t]{2}{*}{$\begin{array}{l}\text { Significant } \\
\text { value }(p)\end{array}$} \\
\hline & $\mathbf{N}$ & $\%$ & $\mathbf{N}$ & $\%$ & $\mathbf{N}$ & $\%$ & \\
\hline \multicolumn{8}{|l|}{ Maternal age } \\
\hline$-\quad \leq 15$ & 2 & 3.2 & 18 & 25.7 & 8 & 28.6 & \multirow[t]{3}{*}{$0.001 *$} \\
\hline$-\quad 15-17$ & 18 & 29.0 & 38 & 54.3 & 14 & 50.0 & \\
\hline$-\quad \geq 17$ & 42 & 67.8 & 14 & 20.0 & 6 & 21.4 & \\
\hline \multicolumn{8}{|l|}{ Educational level } \\
\hline - $\quad$ Primary & 2 & 3.2 & 5 & 7.14 & 3 & 28 & \multirow[t]{3}{*}{0.723} \\
\hline - $\quad$ Secondary & 20 & 32.3 & 24 & 34.3 & 16 & 60 & \\
\hline - $\quad$ University & 40 & 64.5 & 41 & 58.6 & 9 & 90 & \\
\hline \multicolumn{8}{|l|}{ Occupation } \\
\hline - Employer & 10 & 16.1 & 30 & 42.85 & 10 & 35.7 & \multirow[t]{2}{*}{0.358} \\
\hline $\begin{array}{ll}- & \text { Housewife } \\
\end{array}$ & 52 & 83.9 & 40 & 57.14 & 18 & 64.3 & \\
\hline \multicolumn{8}{|l|}{ Types of family } \\
\hline - Nuclear & 42 & 67.7 & 30 & 42.85 & 6 & 21.4 & \multirow[t]{2}{*}{$0.005^{*}$} \\
\hline - $\quad$ Extended & 20 & 32.3 & 40 & 57.14 & 12 & 42.9 & \\
\hline \multicolumn{8}{|l|}{ Income } \\
\hline - $\quad$ Enough & 22 & 35.5 & 60 & 85.8 & 18 & 64.3 & \multirow[t]{2}{*}{$0.001 *$} \\
\hline - $\quad$ Not enough & 40 & 64.5 & 10 & 14.2 & 10 & 35.7 & \\
\hline
\end{tabular}

*Significant at $p \leq 0.05$

Table (5): Correlation between the study subjects according to their reproductive health and maternal confidence

\begin{tabular}{|c|c|c|c|c|c|c|c|}
\hline$\overline{\text { Data }}$ & \multicolumn{2}{|c|}{$\begin{array}{c}\text { Negative } \\
(\mathrm{N}=62)\end{array}$} & \multicolumn{2}{|c|}{$\begin{array}{c}\text { Moderate } \\
(\mathrm{N}=70)\end{array}$} & \multicolumn{2}{|c|}{$\begin{array}{c}\text { Positive } \\
(\mathrm{N}=28)\end{array}$} & $\begin{array}{l}\text { Significant } \\
\text { value (p) }\end{array}$ \\
\hline \multicolumn{8}{|l|}{ Gravidity } \\
\hline - First time & 57 & 91.9 & 66 & 46.3 & 21 & 75 & \multirow{2}{*}{0.855} \\
\hline - $\quad$ Abortion & 5 & 8.1 & 4 & 5.7 & 7 & 25 & \\
\hline \multicolumn{8}{|l|}{ Methods of delivery } \\
\hline - Vaginal delivery & 30 & 48.4 & 40 & 57.2 & 18 & 64.3 & \multirow[t]{2}{*}{$0.001^{*}$} \\
\hline - c- Section & 32 & 51.6 & 30 & 42.8 & 10 & 35.7 & \\
\hline \multicolumn{8}{|l|}{ Gender of baby } \\
\hline - Male & 30 & 48.4 & 62 & 88.6 & 28 & 100 & \multirow[t]{2}{*}{0.470} \\
\hline - $\quad$ Female & 32 & 51.6 & 8 & 11.4 & 0 & 0.0 & \\
\hline \multicolumn{8}{|l|}{ Pregnancy planed } \\
\hline - $\quad$ Planed & 54 & 87.1 & 60 & 85.8 & 26 & 42.8 & \multirow[t]{2}{*}{$0.001 *$} \\
\hline - $\quad$ Not planed & 8 & 12.9 & 10 & 14.2 & 2 & 7.2 & \\
\hline \multicolumn{8}{|c|}{ Attendance of antenatal visits } \\
\hline - Yes & 50 & 80.6 & 60 & 85.8 & 18 & 64.3 & \multirow[t]{2}{*}{$0.000^{*}$} \\
\hline$-\quad$ No & 12 & 19.4 & 10 & 14.2 & 10 & 35.7 & \\
\hline
\end{tabular}

*Significant at $p \leq 0.05$ 


\section{References}

1. Unicef and the Government of Canada: Accelerating the Movement to End Child, Early and Forced Marriage, 2017.

2. World Health Organization. WHO recommendations on postnatal care of the mother and newborn. Geneva: World Health Organization; 2013.

3. Mammie W, Prance, and Celia M. Early motherhood: a qualitative study exploring the experiences of African Australian teenage mothers in greater Melbourne, Australia. BMC Public Health. 2015; 15: 873.

4. WHO. Global health estimates 2015: deaths by cause, age, sex, by country and by region, 2000-2015. Geneva: WHO; 2016.

5. Gjerdingen DK, Froberg DG, Chaloner KM, McGovern PM. Changes in women's physical health during the first postpartum year. Arch Fam Med. 1993; 2(3):277-283.

6. Ruchala PL, James DC. Social support, knowledge of infant development, and maternal confidence among adolescent and adult mothers. J Obstet Gynecol Neonatal Nurs. 1997; 26(6):685-689. doi: 10.1111/j.15526909.1997. tb02743.x.

7. Lugina HI, Christensson $\mathrm{K}$, Massawe $\mathrm{S}$, Nystrom L, Lindmark G. Change in maternal concerns during the 6 weeks postpartum period: a study of primaparous mothers in Dar es Salaam, Tanzania. J Midwifery Womens Health. 2001; 46(4):248-257. doi: 10.1016/S1526-9523(01)00133-7.

8. Badr LK. Further psychometric testing and use of the Maternal Confidence Questionnaire. Issues Compr Pediatr Nurs. 2005; 28(3):16374. doi: 10.1080/01460860500227572.

9. Kuo CP, Chuang HL, Lee SH, Liao WC, Chang LY, Lee MC. Parenting confidence and needs for parents of newborns in Taiwan. Iran $\mathbf{J}$ Pediatr 2012;22(2):177-84. 8

10. United Nations Children's Fund. Accelerating efforts to eliminate child marriage in Africa. New York: UNICEF, 2017.

11. Langlois ÉV, Miszkurka M, Zunzunegui MV, et al. Inequities in postnatal care in low- and middle-income countries: a systematic review and meta-analysis. Bull World Health Organ 2015;93:259-70.

12. Mirghafourvand M, Mohammad-AlizadehCharandabi S, Asghari Jafarabadi M, Soltanpour S. Psychometric properties of the Iranian version of the inventory of functional status after childbirth (IFSAC). Iran Red Crescent Med J. 2017; 19(5):e30210. doi:10.5812/ircmj.30210.
13. African Union. Campaign to end child marriage in Africa. The Effects of Traditional and Religious Practices of Child Marriage on Africa's Socio-Economic Development. A Review of Research, Reports and Toolkits from Africa. 2015. Available at: https://au.int/sites/default/files/documents/ 31018-doc-5465 ccmc africa report.pdf. (Retrieved on: 1 Apr 2018).

14. Gyesaw NYK, Ankomah A. Experiences of pregnancy and motherhood among teenage mothers in a suburb of Accra, Ghana: a qualitative study. Int J Women's Health. 2013; 5:773-80.

15. Josephine D., Self-Perceptions of Parenting among Adolescent Mothers J Perinat Educ. 2017; 16(1): 16-23.

16. Mimmie Claudine Ngum Chi Watts. Early motherhood: a qualitative study exploring the experiences of African Australian teenage mothers in greater Melbourne, Australia BMC Public Health. 2015; 15: 873.

17. Neal S, Channon AA, Chintsanya J. The impact of young maternal age at birth on neonatal mortality: Evidence from 45 low and middle income countries. PLoS One 2018; 13:e0195731.

18. Rikuya H A longitudinal study of socioeconomic status, family processes, and child adjustment from preschool until early elementary school: the role of social competence.

19. Ju-young Ha, Yoon-ji KimFactors Influencing Self-confidence in the Maternal Role among Early Postpartum Mothers Korean Journal of Women Health Nursing 2013; 19(1): 48-56

20. Adedokun O, Adeyemi O, Dauda C. Child marriage and maternal health risks among young mothers in Gombi, Adamawa State, Nigeria: implications for mortality, entitlements and freedoms. Afr Health Sci 2016; 16:986-99. 22. 